\title{
Effect of laser texturing pattern on Ti6Al4V tribocorrosion in a physiological solution
}

Marjetka Conradi PhD

Assistant Professor, Institute of Metals and Technology, University of Ljubljana, Ljubljana, Slovenia (corresponding author:

marjetka.conradi@imt.si)

Tadeja Kosec PhD

Senior Research Associate, Slovenian National Building and Civil

Engineering Institute, Ljubljana, Slovenia

Bojan Podgornik PhD

Associate Professor, Institute of Metals and Technology, University of Ljubljana, Ljubljana, Slovenia
Aleksandra Kocijan PhD

Senior Research Associate, Institute of Metals and Technology, University of Ljubljana, Ljubljana, Slovenia

Janez Kovač PhD

Senior Research Associate, Jožef Stefan Institute, Jamova, Ljubljana, Slovenia

Damjan Klobčar PhD

Associate Professor, Faculty of Mechanical Engineering, University of Ljubljana, Ljubljana, Slovenia

Laser texturing is a process that alters a material's surface properties by modifying its morphology, which can improve properties like adherence, wettability, thermal and electrical conductivity and friction. Here, the effect of laser texturing was studied on an alpha-beta titanium alloy (Ti6Al4V) biomedical material. Two types of patterned surfaces, cross-hatch with varying scan-line separations, $\Delta x=100,180$ and $280 \mu \mathrm{m}$ and dimples of $200 \mu \mathrm{m}$ size, were prepared on the surface of alpha-beta titanium alloy by laser technology. Prepared samples were characterised for their surface properties, such as corrosion, wear-induced corrosion, friction and wettability. Electrochemical and tribocorrosion properties in a physiological solution were studied on the samples with different texture densities of cross-hatch pattern and dimples and compared to the as-received alpha-beta titanium alloy surface. Corrosion rate decreased for laser-textured samples, especially for cross-hatch texture (down to $1 \mu \mathrm{m} / \mathrm{year}$ for $\Delta x=180 \mu \mathrm{m}$ ) when compared to the as-received alpha-beta titanium alloy surface due to the changed laser-induced surface film and wetting properties. Friction coefficient slightly decreased for all laser-textured surfaces, most noticeably for crosshatch patterns, from 0.38 (as-received) down to $0.34(\Delta x=180$ and $280 \mu \mathrm{m})$. The main contribution to total wear in physiological solution increased due to the mechanical wear, which is governed by the removal of the surface oxide layer induced by laser texturing.

Keywords: alpha-beta titanium alloy/surface texturing/tribocorrosion

$\begin{array}{ll}\text { Notation } \\ C_{\mathrm{OF}} & \text { coefficient of friction } \\ E_{\text {corr }} & \text { corrosion potential } \\ h & \text { height } \\ i_{\text {corr }} & \text { corrosion current density } \\ S_{\mathrm{a}} & \text { average surface roughness } \\ V_{\text {mech }} & \text { mechanical wear } \\ V_{\text {syn }} & \text { synergistic contribution to the wear } \\ V_{\text {tot }} & \text { total tribocorrosion wear } \\ v_{\text {corr }} & \text { corrosion rate } \\ \theta^{\mathrm{w}} & \text { static water contact angle }\end{array}$

\section{Introduction}

Titanium-based alloys are well-established materials in a variety of applications. ${ }^{1}$ The alpha-beta titanium alloy (Ti6A14V) is known for its high tensile strength, low density, excellent corrosion resistance and biocompatibility, which makes it an ideal candidate for implants in biomedical applications. ${ }^{2,3}$ However, its tribological response is limited due to its drawbacks related to low surface hardness, high coefficient of friction $\left(C_{\mathrm{OF}}\right)$ and high wear rates. ${ }^{46}$ When exposed to conditions in the human body, the combined interaction of wear and corrosion should also be considered to avoid the failure of the material as a result of tribocorrosion phenomena. ${ }^{1,7}$
A major challenge in biomaterials is the design of surfaces with optimal osseointegration leading to an increased lifespan of the implant. As the durability of materials is mostly governed by the material surface rather than its bulk properties, surface modification technologies serve as suitable approaches to enhance the performance of alpha-beta titanium alloy in biomedical applications. ${ }^{8-11}$ Researchers have therefore focused on improving the tribocorrosion properties by morphological modifications by way of mechanical, ${ }^{12}$ chemical and physical paths, ${ }^{8,9,12}$ or by the application of organic/inorganic coatings. ${ }^{13-15}$ Of the abovementioned approaches, laser texturing has been acknowledged as a promising technique for surface (nano) structuring owing to its high accuracy and flexibility, short processing times, good processing control and environmentfriendly approach. ${ }^{16,17}$ Laser texturing induces changes in the materials' microstructures, resulting in an increased hardness and corrosion resistance. ${ }^{7,18}$ Furthermore, it produces not only controllable periodic surface structures but also thicker oxide layers. ${ }^{19}$ The synergy of simultaneous surface pattern formation and oxidation enables preparation of surfaces with specific target properties with desirable roughness, wettability, topography manipulation from micro- to nanoscale, hardness and corrosion properties. ${ }^{18,20}$ Such modified surface characteristics lead to the 
minimisation of the contact area, continuous lubrication due to the lubricant's storage on the textured surface and the reduction of the abrasive wear due to the entrapment of wear debris. ${ }^{4}$ Manipulation of the size, depth and density of the laser-textured patterns allows an additional degree of freedom in tailoring the tribological behaviour of patterned surfaces. ${ }^{16,21,22}$ There is however a lack of research concerning the tribocorrosion aspects of laser-textured alpha-beta titanium alloy.

Firstly, the general goal of the current study was to prepare a modified surface of the alpha-beta titanium alloy by way of laser texturing and to evaluate tribocorrosion properties related to the biological response in physiological conditions. Secondly, the key aspect of this research was evaluation of the synergistic effect between the corrosion, mechanical properties and wear resistance of the patterned alpha-beta titanium alloy in conditions of the human body.

Laser texturing was applied to prepare two types of patterned surfaces: cross-hatch, with a varying scan-line separation, and dimples. Wear mechanisms associated with tribocorrosion behaviour were studied in Hank's solution to assess the mechanical impact. Electrochemical behaviour of the modified surfaces was analysed using potentiodynamic measurements. Surface hardening of the lasertextured surfaces was confirmed by microhardness measurements. Finally, the structure of the passive film was characterised by X-ray photoelectron spectroscopy (XPS). Optimisation of the alpha-beta titanium alloy's surface properties by way of laser texturing was shown to significantly influence the tribocorrosion response, which is essential for predicting the lifespan of implants.

\section{Materials and methods}

\subsection{Materials}

The Ti alloy used in this investigation was Ti-6Al-4V, grade 5 ( $6 \%$ aluminium, $4 \%$ vanadium) (A.F. Trading s.r.1.). To achieve appropriate mechanical properties, $1.5 \mathrm{~mm}$ thick titanium alloy sheets were heat treated for $1 \mathrm{~h}$ at $830^{\circ} \mathrm{C}\left( \pm 10^{\circ} \mathrm{C}\right)$, the hold time was $1.5 \mathrm{~h}$ and then they were allowed to cool in the furnace. The resulting hardness was $\sim 340 \mathrm{HV} 0.5$. Prior to laser texturing, the sheet was cut into $25 \mathrm{~mm}$ dia. discs, then hand ground with grinding paper of 600 grit $\left(S_{\mathrm{a}}=0.93 \mu \mathrm{m}\right)$ and cleaned with acetone to remove the oxide layer and impurities from the surface.

\subsection{Laser texturing}

A LPKF nanosecond neodymium-doped yttrium aluminium garnet (Nd-YAG) laser equipped with Scanlab SCANgine 14 processing head was used for laser texturing. An F-theta-Ronar lens with a focusing length of $360 \mathrm{~mm}$ and a marking field of $250 \times 250 \mathrm{~mm}$ and a double galvano configuration was used for processing. The laser processed the surface at a $10 \mathrm{~W}$ output power, a wavelength of $1064 \mathrm{~nm}, 33 \mathrm{~ns}$ pulse duration and at $30 \mathrm{kHz}$ of laser-pulse frequency. The laser's focal point was set on the surface of the test coupon. Programming the processing texture with two pattern types, cross-hatch and dimples, made use of SAMLight SCAPS v3.5.5 software. Two texturing speeds of 300 and $100 \mathrm{~mm} / \mathrm{s}$, for the crosshatch and dimples, respectively, were utilised. A $25 \mathrm{~mm}$ dia. surface was completely processed five times on each test coupon. The scanline separation for the cross-hatch pattern was set to $\Delta x=100,180$ and $280 \mu \mathrm{m}$ and $\Delta y$ was kept constant at $280 \mu \mathrm{m}$. The distance between the centres of the circles in the dimples pattern was set to $\Delta x=300 \mu \mathrm{m}$. The target depth of the channels was $20 \mu \mathrm{m}$, and the diameter of the dimples was $200 \mu \mathrm{m}$. Laser processing was performed in ambient conditions and the time needed for processing the test coupon surface with cross-hatch was between 9 and $15 \mathrm{~min}$ (depending on the number of lines on the test coupon), and the surface with dimples was $27 \mathrm{~min}$. The corresponding energy density per test coupon surface was between 17 and $28 \mathrm{~J} / \mathrm{mm}^{2}$ for crosshatch and $51 \mathrm{~J} / \mathrm{mm}^{2}$ for the dimples. It should be noted that the laser spent more time on the same local surface when producing dimples, and consequently heated this local surface to higher temperatures than in the case of cross-hatch processing.

\subsection{Surface characterisation}

Scanning electron microscope (SEM) analysis using a field-emission SEM JEOL JSM-6500F was employed to investigate the morphology of the laser-textured surfaces. An electron microscope JEOL JSM-IT500LV with an Aztec Live Advanced ULTIM 65 detector (Oxford Instruments, 2019) equipped with energy-dispersive spectroscopy (EDX) was used to observe and analyse the wear tracks at an accelerating voltage of $20 \mathrm{kV}$. A Taylor Hobson profilometer (Taylor Hobson Precision, Surtronic 25 France, 2010) was used to analyse the laser channels and wear volume. Optical 3D metrology system, model Alicona Infinite Focus (Alicona Imaging $\mathrm{GmbH}$ ) with IF-MeasureSuite (Version 5.1) software was used for the surface roughness analysis. Five measurements of the average surface roughness, $S_{\mathrm{a}}$, per sample were performed at magnification of $20 \times$ with a lateral resolution of $0.9 \mu \mathrm{m}$ and a vertical resolution of $50 \mathrm{~nm}$. The size of the analysed area was $1.43 \times 1.08 \mathrm{~mm}^{2}$.

\subsection{Potentiodynamic measurements}

The potentiodynamic measurements were performed in Hank's solution, containing $8 \mathrm{~g} / 1$ sodium chloride $(\mathrm{NaCl}), 0.40 \mathrm{~g} / \mathrm{l}$ potassium chloride $(\mathrm{KCl}), 0.35 \mathrm{~g} / 1$ sodium bicarbonate $\left(\mathrm{NaHCO}_{3}\right), 0.25 \mathrm{~g} / \mathrm{l}$ sodium phosphate monobasic dihydrate $\left(\mathrm{NaH}_{2} \mathrm{PO}_{4} \cdot 2 \mathrm{H}_{2} \mathrm{O}\right), 0.06 \mathrm{~g} / \mathrm{l}$ sodium phosphate dibasic dihydrate $\left(\mathrm{Na}_{2} \mathrm{HPO}_{4} \cdot 2 \mathrm{H}_{2} \mathrm{O}\right), 0.19 \mathrm{~g} / \mathrm{l}$ calcium chloride dihydrate $\left(\mathrm{CaCl}_{2} \cdot 2 \mathrm{H}_{2} \mathrm{O}\right), 0.41 \mathrm{~g} / 1$ magnesium chloride hexahydrate $\left(\mathrm{MgCl}_{2} \cdot 6 \mathrm{H}_{2} \mathrm{O}\right), 0.06 \mathrm{~g} / \mathrm{l}$ magnesium sulfate heptahydrate $\left(\mathrm{MgSO}_{4} \cdot 7 \mathrm{H}_{2} \mathrm{O}\right), 1 \mathrm{~g} / \mathrm{l}$ glucose, at $\mathrm{pH}=7.8$ and room temperature. A three-electrode system with the test specimen embedded as the working electrode, a saturated calomel electrode (SCE, $0.242 \mathrm{~V}$ against SHE) as the reference electrode and a platinum mesh as the counter electrode was used. The potentiodynamic curves were measured at a scan rate of $1 \mathrm{mV} / \mathrm{s}$ on a potentiostat/galvanostat/FRA instrument (BioLogic ${ }^{\circledR}$ SP-300 with EC-Lab ${ }^{\circledR}$ V11.27 software) after stabilisation at the open-circuit potential (OCP) for $1 \mathrm{~h}$ prior to the measurement. Potentiodynamic measurement started at $-250 \mathrm{mV}$ against $E_{\text {corr }}$ in the anodic direction up to until $1 \mathrm{~mA} / \mathrm{cm}^{2}$ was reached. All the measurements were repeated three times. 


\subsection{Wettability}

The static water-contact angles were measured on the as-received and laser-textured alpha-beta titanium alloy surfaces using a surfaceenergy-evaluation system (Advex Instruments s.r.o.). Water drops of $5 \mu \mathrm{l}$ were deposited randomly on five different spots of the lasertextured surface to avoid the influence of texturing, roughness and gravity on the shape of the drop. The contact angle was determined using Young-Laplace fitting. The measurements were performed at $22^{\circ} \mathrm{C}$ and ambient humidity.

\subsection{Tribocorrosion testing}

The tribocorrosion study was conducted on a reciprocal tribometer (pin-on-disc and a reciprocating tribometer Tribotechnic, 2009, France) with a $6 \mathrm{~mm}$ aluminium oxide $\left(\mathrm{Al}_{2} \mathrm{O}_{3}\right)$ counter ball. The experimental setup is schematically presented in Figure 1.

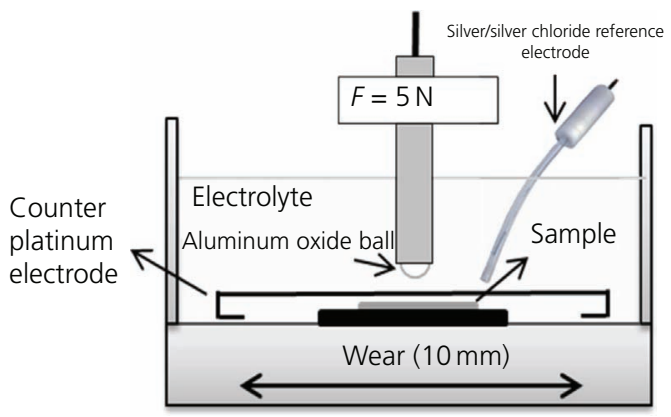

Figure 1. Tribocorrosion cell with a three-electrode system and an aluminium oxide counter body with the working electrode fully immersed in the test solution
The normal load was $5 \mathrm{~N}$ (nominal contact pressure of $975 \mathrm{MPa}$ and contact radius of $0.1 \mathrm{~mm}$ according to the Hertz elastic theory), with an average sliding speed of $5 \mathrm{~mm} / \mathrm{s}$. The reciprocal wear was conducted in the $y$-direction of the laser channels. The wear track length was $10 \mathrm{~mm}$ and the sliding continued for $1800 \mathrm{~s}$, corresponding to a total sliding distance of $9 \mathrm{~m}$. The frictional force and the $C_{\mathrm{OF}}$ were monitored continuously during the test. The tribo-electrochemical three-electrode cell consisted of a working electrode with an electrical contact, a platinum wire serving as the counter electrode, and a silver/silver chloride $(\mathrm{Ag} / \mathrm{AgCl})$ reference electrode. The tribocorrosion experiments were performed in Hank's solution at room temperature. The wear mechanisms were studied by comparing the wear in the cathodic domain in Hank's solution for an evaluation of the mechanical impact.

\subsection{Hardness measurement}

Vickers hardness was determined by means of an indentation hardness tester, using a Vickers indenter at a test load of $0.1 \mathrm{~N}$ (HV0.01) and 4.9 N (HV0.5), and microscopic enlargements of $100 \times$. At least five indents were done for each specimen and average value calculated.

\subsection{X-ray photoelectron spectroscopy (XPS)}

XPS analyses were carried out on the TFA XPS spectrometer produced by Physical Electronics equipped with aluminiummonochromatic X-ray source of photon energy $1486.6 \mathrm{eV}$ and a hemispherical electron-energy analyser. The analysed area was $0.4 \mathrm{~mm}$ in diameter. The high-energy-resolution XPS spectra were acquired at about $0.6 \mathrm{eV}$ and a pass energy of $29 \mathrm{eV}$. A neutraliser electron gun was used to reduce the surface charging. XPS depth profiling was performed by the $1-\mathrm{keV} \mathrm{Ar}^{+}$ion beam rastering over an area of $3 \times 3 \mathrm{~mm}$ with an etching rate of $1.0 \mathrm{~nm} / \mathrm{min}$.
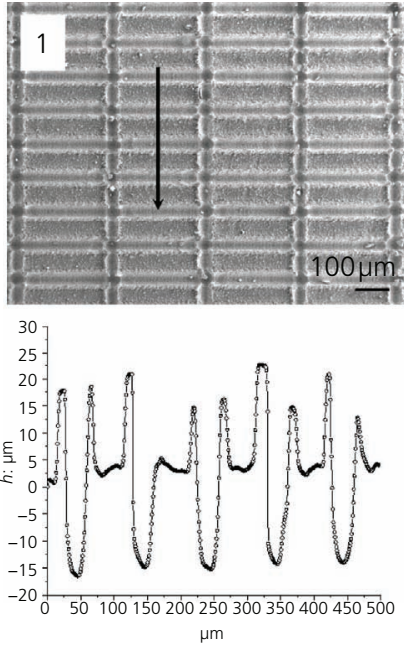

$S_{a}=(10.1 \pm 0.2) \mu m$
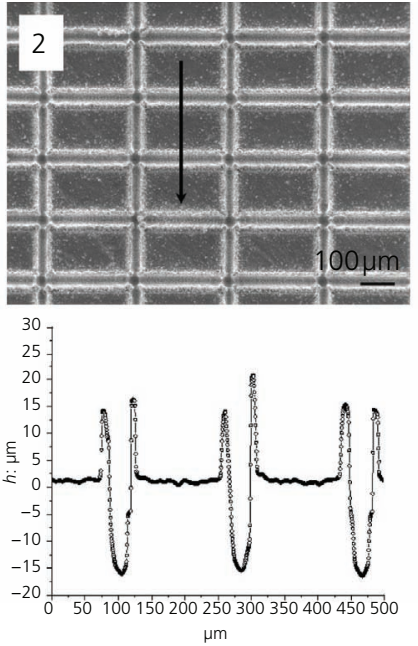

$S_{a}=(6.8 \pm 0.3) \mu m$
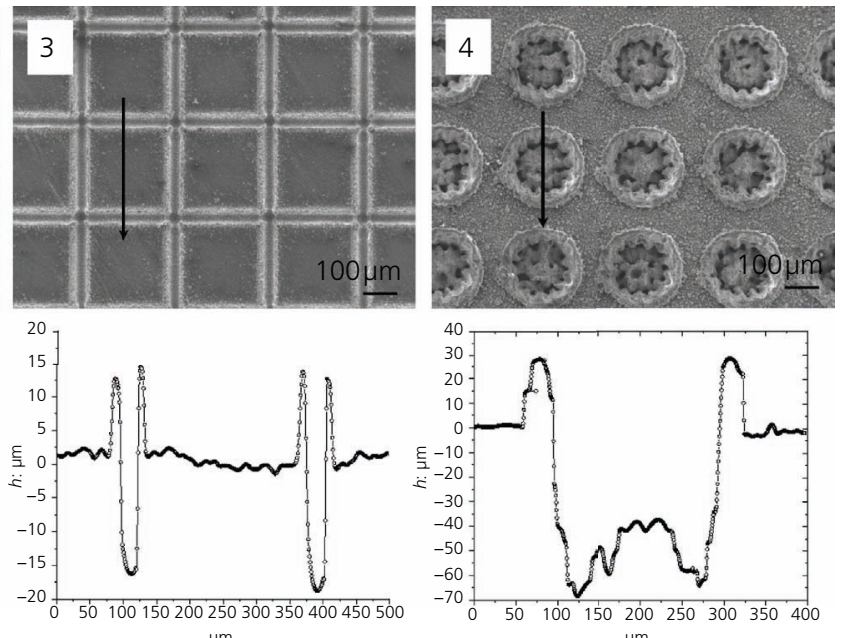

$S_{a}=(4.7 \pm 0.2) \mu m$

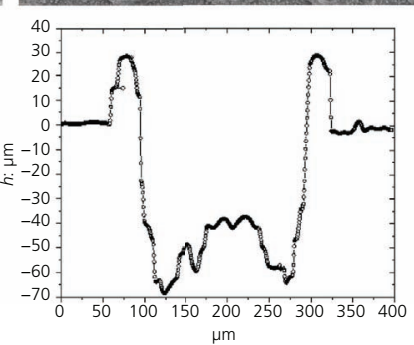

$S_{a}=(9.2 \pm 0.4) \mu m$

Figure 2. Morphological details of the laser-textured surfaces with the cross-hatch pattern having a varying scan-line separation: $\Delta x=100$ (1), 180 (2) and $280 \mu \mathrm{m}$ (3) and dimples (4). The profile measurements presented the SEM images and reveal the depth of the laser channels and the height of the bulges. The arrows on the SEM images indicate the direction of the profile measurements, also corresponding to the sliding direction. The corresponding values of the average surface roughness, $S_{a}$, are given in each SEM image 
Effect of laser texturing pattern on Ti6Al4V tribocorrosion in a physiological solution

Conradi, Kosec, Podgornik et al.

\section{Results and discussion}

\subsection{Surface morphology}

Figure 2 presents the morphology of the surface patterns produced with selected laser-texturing parameters. The cross-hatch pattern is characterised by channels in the $x-y$ directions, and the variable scanline separation in the $x$ direction (sliding direction) defines the samples' texture. The texture density, which is defined as the ratio between the laser-textured surface (cavity) and the total surface area, is reduced from about $40 \%$ to $27 \%$ and $20 \%$ with an increasing scan-line separation from $\Delta x=100$ to $280 \mu \mathrm{m}$. The cross-section metallographic analysis (Figure 3(a)) indicates that the laser channels are approximately $30 \mu \mathrm{m}$ wide and $20 \mu \mathrm{m}$ deep. At the edge of the channels there are bulges of ejected material up to $20 \mu \mathrm{m}$ high and with a hardness of up to $1500 \mathrm{HV0.01}$, as determined by measurements on the polished metallographic cross-section (Figure 3). Laser texturing resulted in a 2-3 $\mu \mathrm{m}$ thick hardened layer over the whole surface of the channels. As varying the scan-line separation defines not only the morphology but also the roughness of the surface, the average surface roughness, $S_{\mathrm{a}}$, for all the samples was also evaluated. According to the morphology and the texture density, $S_{\mathrm{a}}$ decreases with increasing scan-line separation from $10.1 \mu \mathrm{m}(\Delta x=$ $100 \mu \mathrm{m})$ to $6.8 \mu \mathrm{m}(\Delta x=180 \mu \mathrm{m})$ and $4.7 \mu \mathrm{m}(\Delta x=280 \mu \mathrm{m})$. The values of $S_{\mathrm{a}}$ are given in Figure 2. Compared to as-received, nontextured alpha-beta titanium alloy surface with $S_{\mathrm{a}}=0.9 \mu \mathrm{m}$, laser texturing significantly increases the surface roughness up to ten times for the sample with the highest texture density, $\Delta x=100 \mu \mathrm{m}$.

The dimple pattern (Figure 2, sample 4) is characterised by $200 \mu \mathrm{m}$ dia. circles and a distance of $300 \mu \mathrm{m}$ between the centres of the circles. The texture density of the dimple-patterned surfaces is about $30 \%$ and the corresponding average surface roughness, $S_{\mathrm{a}}$, is $9.2 \mu \mathrm{m}$. The height profile of the dimples is defined by their depth, reaching $70 \mu \mathrm{m}$ at the inner edge of the circle, whereas the centre of the dimple is shallower with a depth of less than $40 \mu \mathrm{m}$. At the outer edge of the circles, the characteristic bulges of the ejected, hardened material were again observed, up to $30 \mu \mathrm{m}$ above the non-textured part of the surface. In the case of the dimples, a much thicker hardened layer of up to $20 \mu \mathrm{m}$ can be observed (Figure 3(b)), although showing the same hardness of about 1500 HV0.01. In all cases, cross-hatch patterns and dimples, the bulk material retained a hardness of $\sim 340$ HV0.01.

\subsection{Potentiodynamic measurements}

Potentiodynamic polarisation curves of the as-received alpha-beta titanium alloy, the cross-hatch laser-textured samples (Sample 1 with $\Delta x=100 \mu \mathrm{m}$, Sample 2 with $\Delta x=180 \mu \mathrm{m}$, Sample 3 with $\Delta x=$ $280 \mu \mathrm{m}$ ) and those with dimples (Sample 4) measured in Hank's solution are presented in Figure 4 and accompanied with corrosion potentials $\left(E_{\text {corr }}\right)$, corrosion current densities $\left(i_{\text {corr }}\right)$, static water contact angles $\left(\theta^{\mathrm{w}}\right)$ and calculated values of the corrosion rates $\left(v_{\text {corr }}\right)$ in Table 1. The substantial increase of $E_{\text {corr }}$ and the decrease of $i_{\text {corr }}$ and $v_{\text {corr }}$ were observed for the laser-textured surfaces in comparison with the as-received alpha-beta titanium alloy sample (Table 1).

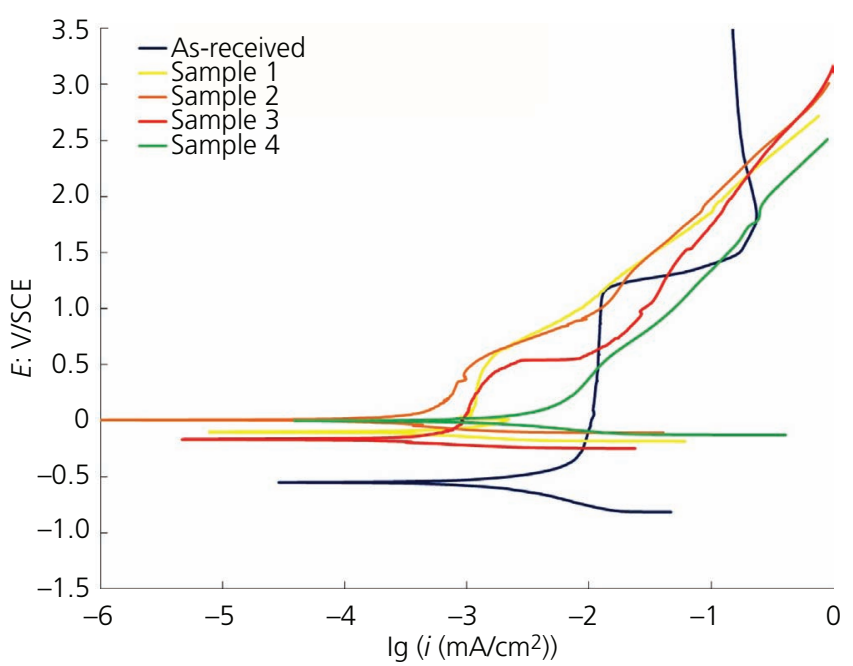

Figure 4. Potentiodynamic polarisation curves of as-received alphabeta titanium alloy, cross-hatch laser-textured (Sample 1 with $\Delta x=$ $100 \mu$ m, Sample 2 with $\Delta x=180 \mu$ m, Sample 3 with $\Delta x=280 \mu \mathrm{m}$ ) and with dimples (Sample 4) in Hank's solution. SCE, saturated calomel electrode

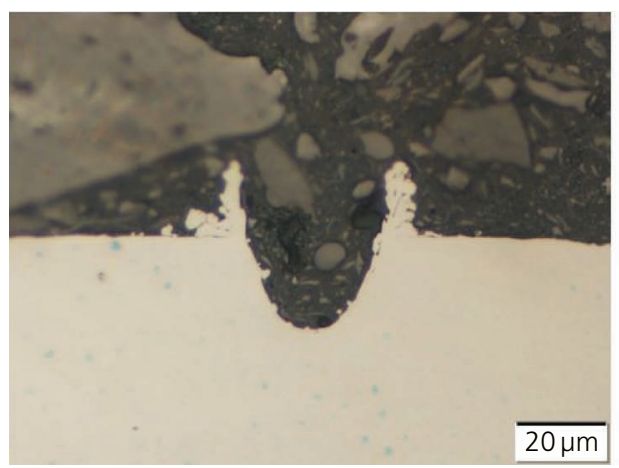

(a)

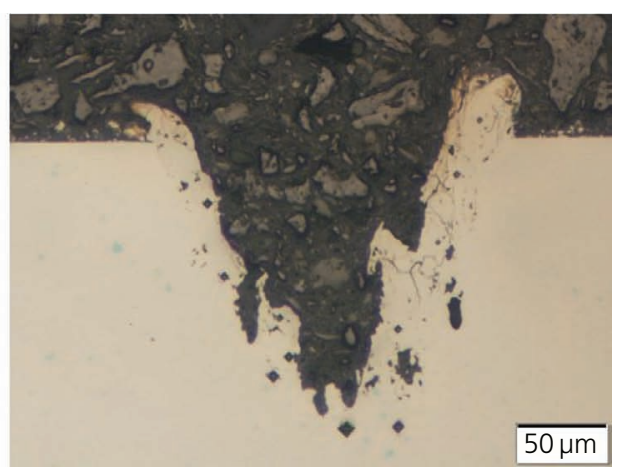

(b)

Figure 3. Cross-section of the laser-textured alpha-beta titanium alloy sample: (a) channels in cross-hatch pattern and (b) dimples 
This trend was more pronounced for the cross-hatch laser-textured surfaces (Samples 1, 2 and 3) than for the dimples (Sample 4). The improved corrosion resistance for the cross-hatch laser-textured samples can be explained by the increased hydrophobicity compared to the as-received, non-textured sample. The as-received alpha-beta titanium alloy surface was neutrally wet with a static water-contact angle, $\theta^{\mathrm{w}} \sim 90^{\circ}$. After laser texturing with the cross-hatch patterns, the surfaces of all three Samples 1-3 became strongly hydrophobic with a $\theta^{\mathrm{W}}$ around $135^{\circ}$ (Table 1), which induced a significant decrease in the corrosion rate from around $18 \mu \mathrm{m} /$ year to $1-4 \mu \mathrm{m} /$ year. The dimple-textured surface was, on the other hand, superhydrophilic $\theta^{\mathrm{w}}<3^{\circ}$ ); however, the corrosion rate decreased slightly compared with the as-received sample, from around 18 to $12 \mu \mathrm{m} /$ year. This can be explained by the grain refinement and the formation of the $\alpha^{\prime}$-martensite of the laser-textured surfaces, which was confirmed by electron backscatter diffraction and published in a separate paper. ${ }^{18}$ Additionally, the increased corrosion performance of the laser-textured Ti-alloy surfaces can be attributed to the formation of the laser-induced layer with excess amount of oxygen $(\mathrm{O}),^{23}$ as indicated by the cross-section analysis in Figure 3 and confirmed by XPS analysis, explained later in the text.

\subsection{Tribocorrosion}

OCP measurements during tribocorrosive wear in Hank's solution for the as-received alpha-beta titanium alloy and laser-textured samples are shown in Figure 5. For all the samples, the OCP was measured first until a stable potential was achieved. Then a $5 \mathrm{~N}$ normal load was applied to initialise the reciprocating sliding and finally, after sliding for $1800 \mathrm{~s}$, the slow increase in the potential towards the initial value was monitored. For the as-received alpha-beta titanium alloy sample, the measured OCP decreased from 0.03 to $-0.8 \mathrm{~V}$ against silver/silver chloride after the application of the load (Figure 5(a)). During the sliding period, a further decrease in the potential was observed, fluctuating around $-0.9 \mathrm{~V}$. The $C_{\mathrm{OF}}$ in Hank's solution varied around 0.38 during the sliding, with the highest value being about 0.5 .

In the case of the cross-hatch laser-textured alpha-beta titanium alloy surface with $\Delta x=100 \mu \mathrm{m}$ (sample 1), the OCP decreased from 0.17 to $-0.4 \mathrm{~V}$ and slightly decreased during further sliding (Figure 5(b)). The COF decrease was observed in the running-in period and then stabilised at around 0.35 (Table 2). For the alpha-beta titanium alloy laser-textured cross-hatch surface with $\Delta x=180 \mu \mathrm{m}$ (Sample 2), where less laser impact was introduced to the surface, the OCP dropped from 0.37 to $-0.3 \mathrm{~V}$ at the start of the sliding and decreased

Table 1. Electrochemical parameters and corrosion rate, deduced from the potentiodynamic curves accompanied by corresponding static water-contact angles $\left(\theta^{\mathrm{w}}\right)$

\begin{tabular}{lrccc} 
Sample & \multicolumn{1}{c}{$\boldsymbol{E}_{\text {corr: }} \mathbf{V}$} & $\boldsymbol{i}_{\text {corr: }}$ uA & $\boldsymbol{V}_{\text {corr }}: \boldsymbol{\mu m} /$ year & \multicolumn{1}{c}{$\boldsymbol{\theta}^{\mathbf{w}} \mathbf{~}^{\circ}$} \\
As-received & $-579 \pm 9$ & $2.0 \pm 0.7$ & $17.6 \pm 0.8$ & $90.1 \pm 1.0$ \\
Sample 1 & $-124 \pm 6$ & $0.5 \pm 0.2$ & $4.0 \pm 0.5$ & $134.2 \pm 1.5$ \\
Sample 2 & $4 \pm 1$ & $0.1 \pm 0.1$ & $1.0 \pm 0.3$ & $136.7 \pm 1.1$ \\
Sample 3 & $-177 \pm 7$ & $0.2 \pm 0.1$ & $1.5 \pm 0.3$ & $135.0 \pm 1.5$ \\
Sample 4 & $-11 \pm 1$ & $1.3 \pm 0.4$ & $11.7 \pm 0.7$ & $<3$
\end{tabular}

further to $-0.4 \mathrm{~V}$ (Figure 5(c)). The COF was similar to Sample 1, varying around 0.34 . However, after $500 \mathrm{~s}$, a step with a slight decrease of the COF and a minor increase of the potential was observed, probably due to the levelling of the wear-track surface. For the low pattern cross-hatch density (sample 3), the OCP before and during sliding is shown in Figure 5(d). The potential decreases from 0.3 to $-0.3 \mathrm{~V}$ and further to $-0.4 \mathrm{~V}$ during the sliding. Also in this case, the COF stabilised at around 0.34 after the running-in period. Figure $3 €$ shows the OCP for the dimple-textured alpha-beta titanium alloy surface (sample 4), where the potential dropped from 0.21 to $-0.5 \mathrm{~V}$ and further to $-0.65 \mathrm{~V}$ during the sliding. Here, high fluctuations in the OCP were observed during sliding, probably due to the changes in the contact surfaces during bulge removal. Fluctuations of the COF around 0.37 were observed as well.

Table 2 collects the tribocorrosion results and accompanying COFs. The COF is the highest for the as-received alpha-beta titanium alloy. The results indicate that surface laser texturing with the cross-hatch pattern reduces the friction under lubricated conditions in Hank's solution, being the consequence of martensitic microstructure on the laser-processed surfaces, which can be harder than the native alphabeta titanium alloy ${ }^{24}$ and micro-hydrodynamic effects. ${ }^{25,26}$ The positive effect of the laser- texturing increases with the reduced texture density, the COF being the lowest for the broadest cross-hatch pattern (Sample 3). In the case of dimples, the COF is high, close to the value for the as-received sample. Increase in friction can be attributed to thicker hardened brittle layer and larger bulges around the dimples, which break during sliding and cause a ploughing effect. For comparison, the COFs measured in the cathodic regime are listed in Table 2 as well. The COF under the cathodic regime is very similar to the COF measured during the tribocorrosion experiment in Hank's solution, indicating the dominant contribution of the mechanical wear.

At the end of the sliding, the potential slowly returned to the initial value. As indicated in Figure 5(a), the repassivation times were estimated by plotting tangents to the OCP measurements just after the sliding ended and when the OCP approached the initial value. The repassivation times were shorter $(<100 \mathrm{~s})$ for the asreceived and dimple textured sample (Sample 4), which correlated with the lower corrosion stability, as deduced from the

Table 2. Tribocorrosion results for the alpha-beta titanium alloy in Hank's solution and in the cathodic regime

\begin{tabular}{lcccc} 
Sample & $\boldsymbol{\Delta E / V}$ & $\begin{array}{c}\text { Repassivation } \\
\text { time: } \mathbf{s}\end{array}$ & $\boldsymbol{C}_{\text {OF-Hank }}$ & $\begin{array}{c}\mathrm{C}_{\text {OF- }} \\
\text { cathodic }\end{array}$ \\
\hline As-received & 0.950 & 80 & $0.38 \pm$ & $0.39 \pm$ \\
Sample 1 & 0.596 & 143 & 0.02 & 0.02 \\
& & & 0.01 & $0.36 \pm$ \\
Sample 2 & 0.732 & 141 & $0.34 \pm$ & $0.35 \pm$ \\
& & & 0.01 & 0.02 \\
Sample 3 & 0.745 & 105 & $0.34 \pm$ & $0.35 \pm$ \\
& & & 0.01 & 0.02 \\
Sample 4 & 0.859 & 48 & $0.37 \pm$ & $0.36 \pm$ \\
& & & 0.02 & 0.01
\end{tabular}




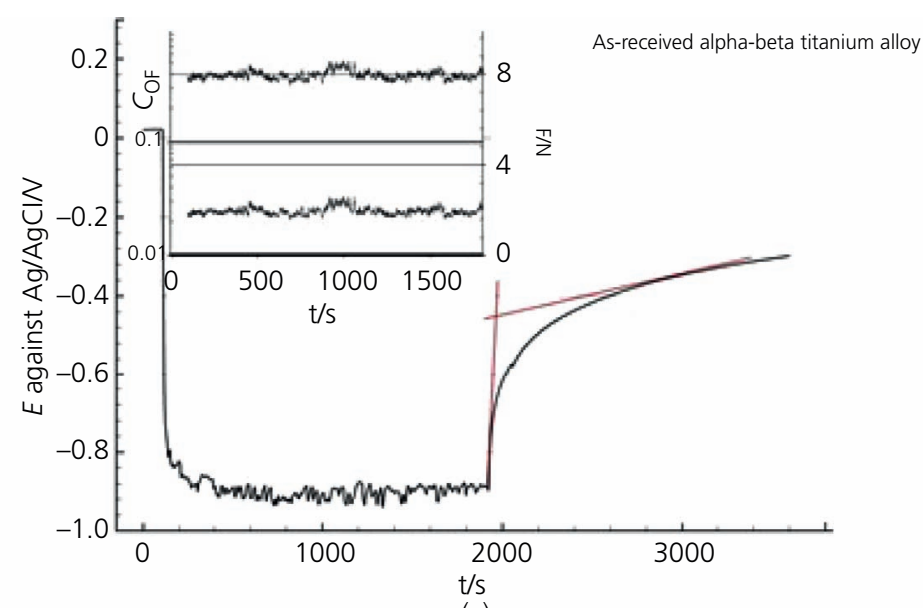

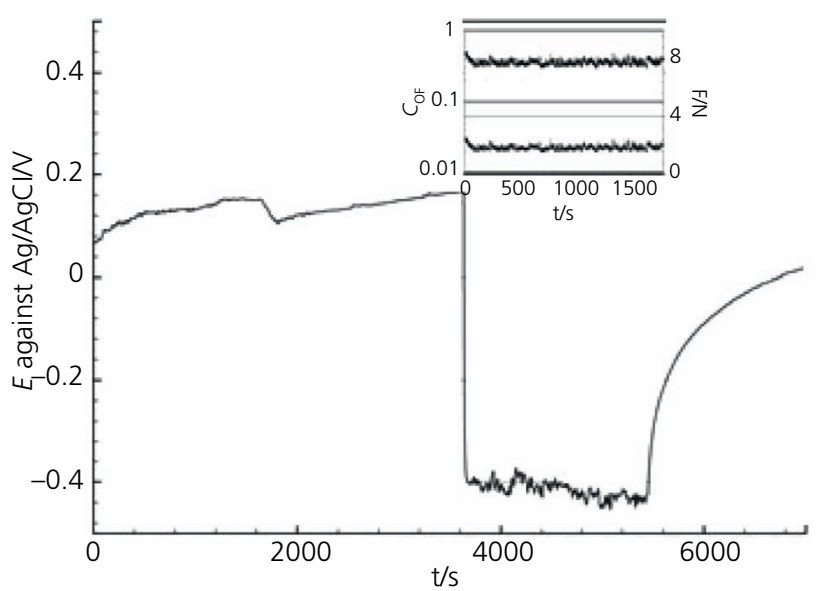

(b)

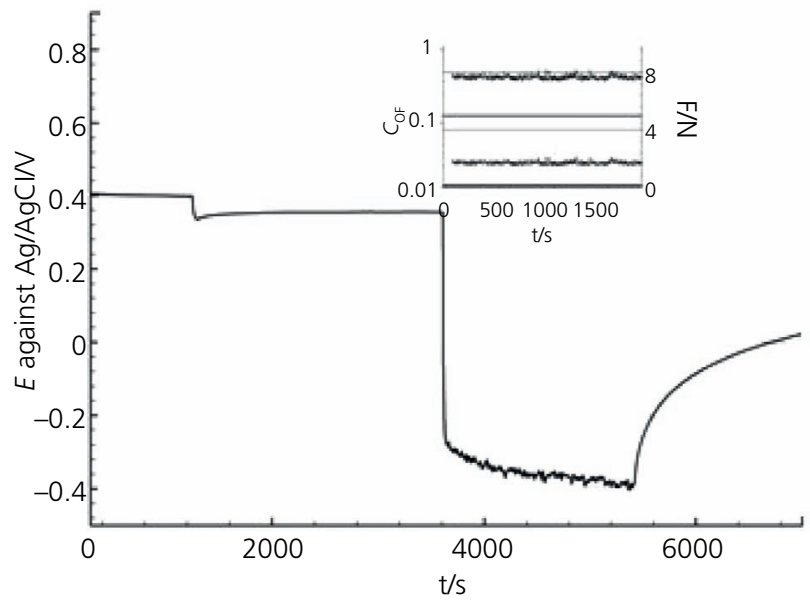

(d)

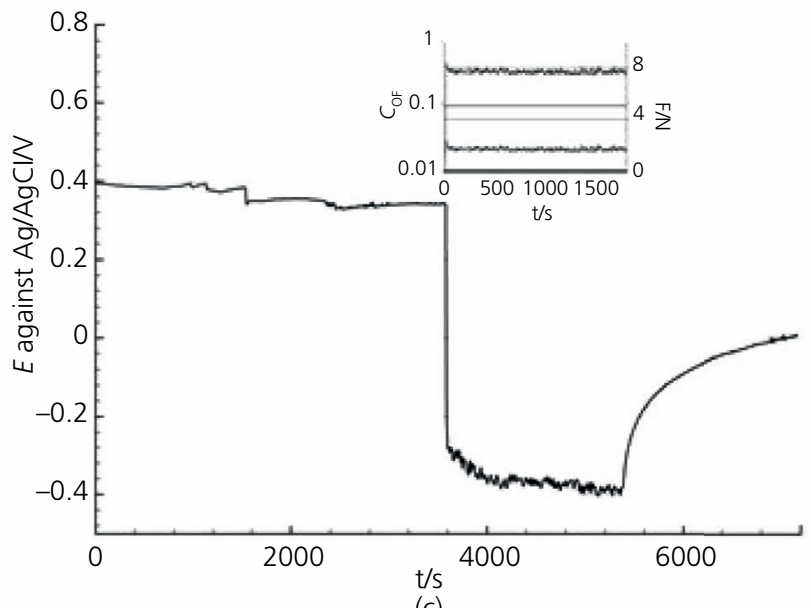

(c)

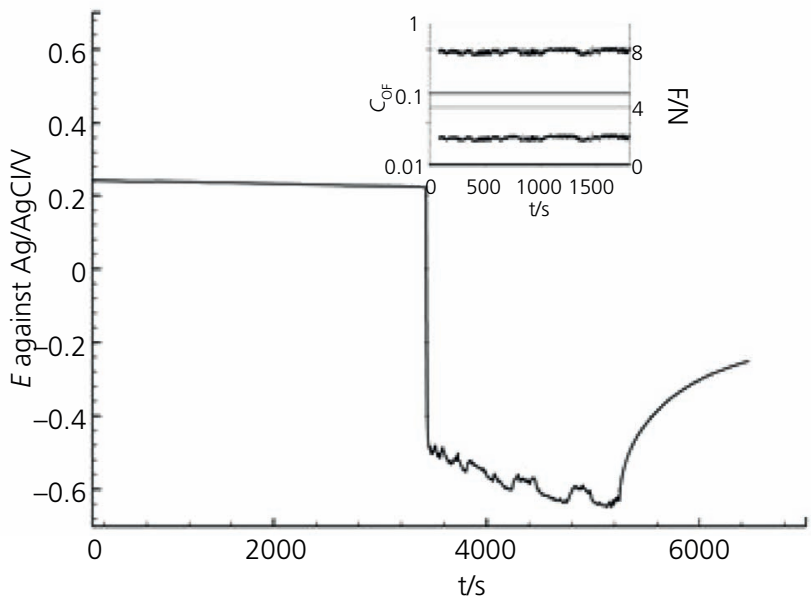

(e)

Figure 5. OCP measurements for (a) as-received alpha-beta titanium alloy, for cross-hatch laser-textured samples: (b) Sample 1 with $\Delta x=$ $100 \mu \mathrm{m}$; (c) Sample 2 with $\Delta x=180 \mu \mathrm{m}$; (d) Sample 3, with $\Delta x=280 \mu \mathrm{m}$ and (e) dimples (Sample 4) in Hank's solution. The insets in each figure show the $\mathrm{C}_{\mathrm{OF}}$ and force during reciprocal wear

potentiodynamic measurements. This can be explained by the rapid rebuilding of a few nanometre oxide layer in the case of the as-received sample and by the combined effect of the superhydrophilicity and the increased oxide layer thickness in the case of the dimples. For cross-hatch laser-textured Samples $1-3$, the repassivation times were longer, more than $100 \mathrm{~s}$, which 
was due to the larger surface of the worn, thick oxide in the wear track as well as the increased hydrophobicity (Table 1). A similar trend was observed for the difference between the OCP value before and after the lubricated sliding, where the highest potential change was measured for the as-received alpha-beta titanium alloy and dimple-textured sample (Sample 4) at around 0.9 V. The potential change for all the cross-hatch textured samples was lower, from around 0.6 to $0.7 \mathrm{~V}$, with a decreasing texture density.

\subsection{Wear}

The wear tracks were observed by SEM and the wear-volume loss was evaluated by multiple profile measurements across the wear track. The calculated Hertz contact pressure of $975 \mathrm{MPa}$ was similar to the yield strength of the alpha-beta titanium alloy $(950 \mathrm{MPa})$. Therefore, no drastic phase transformations can be expected. However, some local plastic deformation and surface hardening, especially for the textured surfaces with a reduced contact area are anticipated, which could affect the estimated wear volume. Hardness measurements within the wear track confirm the strain-hardening effect, which is negligible for the non-textured sample (hardness increase to about 350 HV0.5), slightly more pronounced for the cross-hatch pattern $(\sim 380$ HV0.5) and the largest for the dimples (> 400 HV0.5). As reported by Conradi et al. ${ }^{18}$ laser-texturing affected the original microstructure up to $2 \mu \mathrm{m}$ deep where melting and rapid solidification occured. Significant surface hardening for this type of laser texturing was further explained due to the formation of $\alpha^{\prime}$-martensite on the form of very fine needles.

SEM/EDS images/analyses of the as-received alpha-beta titanium alloy and two representative laser-textured samples of the cross-hatch and dimple textures (Samples 2 and 4) after the tribocorrosion experiments are shown in Figure 6 and Table 3. The locations of the EDS analyses are denoted in Figures 6(a), 6(c) and 6(e). The morphologies of the wear tracks are presented in Figures 6(b), 6(d) and 6(f). A combination of different wear mechanisms was observed. One wear mechanism was abrasion, observed by parallel grooves and scratches due to sliding of the harder aluminium oxide ball against the softer alpha-beta titanium alloy material. This wear mechanism was more dominant for the laser-textured surfaces, especially for high texturing densities (i.e. Samples 1, 2 and 4). The other wear mechanism was delamination, observed as micro-cracks and removed patches of alpha-beta titanium alloy surface in the wear track formed due to the repeated loading and unloading during the reciprocating sliding. The cracks were presented with parallel arrows, while inclined arrows pointed to the presence of delaminated patches of surface oxides. A mild form of oxidative wear was also observed in the deepest grooves (Figure 6(f)).

EDS analyses were used for the elemental composition of the surface outside the wear tracks, inside the wear tracks and at the places where accumulated material was found in order to study changes during tribocorrosive wear. The results showed that the amount of oxygen outside the wear track was higher than in the wear track, suggesting that the layer with excess amount of oxygen was reciprocally removed from the wear track. However,

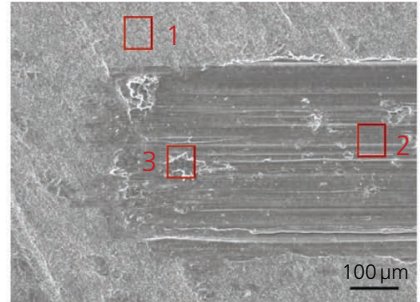

(a)

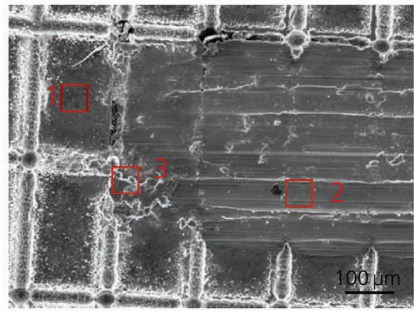

(c)

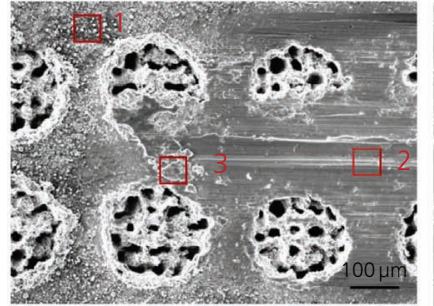

(e)

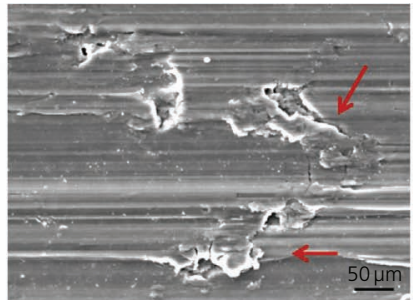

(b)

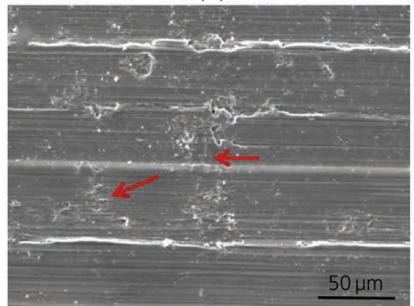

(d)

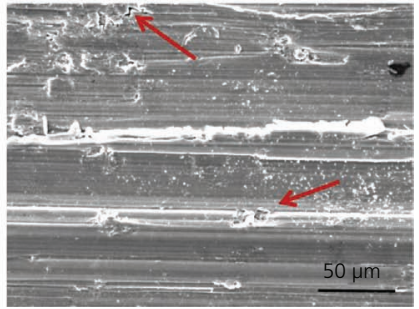

(f)
Figure 6. SEM images of wear tracks on alpha-beta titanium alloy after tribocorrosion experiment in Hank's solution: (a) and (b) asreceived alpha-beta titanium alloy; (c) and (d) laser-textured Sample 2 with $\Delta x=180 \mu m$; and (e) and (f) Sample 4 (dimples)

the amount of oxygen outside the wear track (unworn surface) on the laser-textured samples, especially for the dimple textured sample, was significantly higher than the as-received alpha-beta titanium alloy sample, similar to the observations reported by Sefer $e t a l .^{23}$ The amount of oxygen in the worn particles at the edges of the wear track was higher again in all the observed wear tracks, indicating that the layer with excess amount of oxygen was removed from the wear track. The EDS analyses of Samples 1,2 and 3 were very similar in composition when observing the surface outside the wear track, inside the wear track or at the worn particles at the edges. Therefore, only the composition for Sample 2 is given in Table 3 .

The width and depth of the wear tracks were measured with the profilometer and the wear volumes calculated based on multiple profiles (3D profilometric measurement). As shown in Figure 7, the wear track on the as-received sample was the smallest (narrower and shallow) compared to the laser-textured samples. The widest wear tracks were measured on the dimple (Sample 4) and cross-hatch laser-textured surface with the highest texture density (Sample 1). The width of wear tracks was reduced with lower texturing density (Samples 2 and 3). In the case of dimples, the wear-track width was about $600 \mu \mathrm{m}$ and with a depth of 
Table 3. EDS analyses of the worn surfaces of as-received alpha-beta titanium alloy and two representative laser-textured surfaces, crosshatch (Sample 2) and dimples (Sample 4), after tribocorrosion testing in Hank's solution

\begin{tabular}{llccccccccc} 
Sample & \multicolumn{1}{c}{ EDS wt. $\%$} & Titanium & Aluminium & Vanadium & Oxygen & Carbon & Phosphorus & Silicon Calcium Chlorine \\
As-received & Outside the wear track-1 & 77.5 & 5.3 & 3.6 & 9.2 & 4.7 & - & - & - & - \\
& In the wear track-2 & 82.5 & 5.0 & 3.8 & 5.3 & 3.3 & - & 0.10 & - & - \\
\multirow{5}{*}{ Sample 2 } & Worn particle-3 & 70.9 & 4.4 & 3.1 & 15.8 & 4.2 & 0.70 & 0.10 & - & 0.80 \\
& Outside the wear track-1 & 74.3 & 3.8 & 3.3 & 13.4 & 5.2 & 0.02 & 0.10 & - & - \\
& In the wear track-2 & 83.9 & 4.5 & 3.6 & 5.0 & 2.9 & 0.06 & 0.06 & - & 0.02 \\
\multirow{5}{*}{ Sample 4 } & Worn particle-3 & 70.0 & 4.3 & 2.7 & 17.7 & 6.5 & 0.44 & - & - & 0.46 \\
& Outside the wear track-1 & 54.7 & 3.0 & 2.4 & 32.1 & 7.4 & 0.14 & 0.17 & 0.15 & 0.01 \\
& In the wear track-2 & 81.5 & 5.3 & 3.5 & 6.1 & 3.3 & - & 0.08 & - & 0.01 \\
& Worn particle-3 & 73.1 & 4.8 & 3.0 & 14.2 & 4.2 & 0.03 & 0.07 & - & 0.32
\end{tabular}
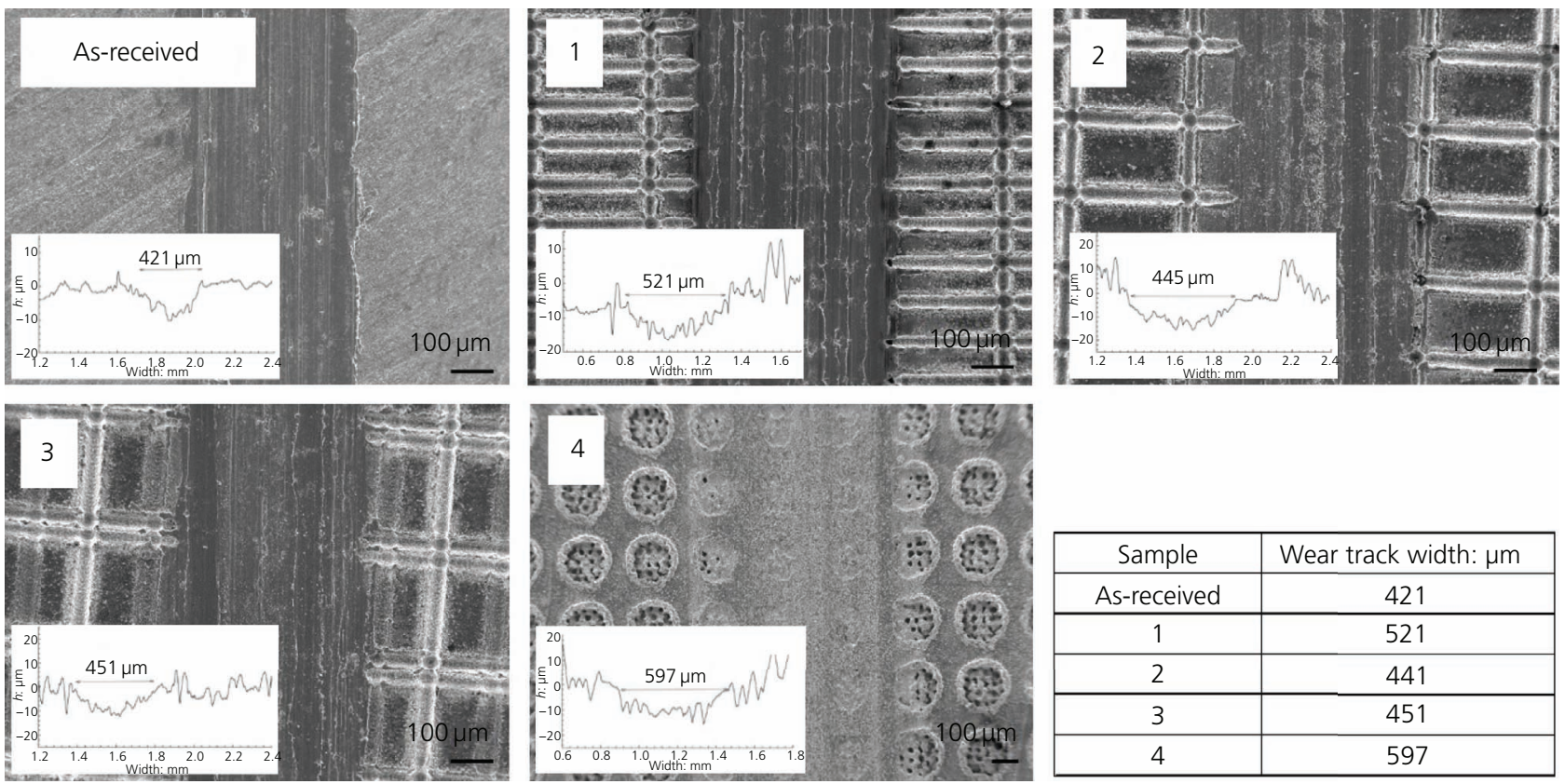

\begin{tabular}{|c|c|}
\hline Sample & Wear track width: $\mu \mathrm{m}$ \\
\hline As-received & 421 \\
\hline 1 & 521 \\
\hline 2 & 441 \\
\hline 3 & 451 \\
\hline 4 & 597 \\
\hline
\end{tabular}

Figure 7. SEM images and depth profiles of the wear tracks on alpha-beta titanium alloy after tribocorrosive experiments in Hank's solution. Corresponding widths of the wear tracks are listed on each inset

$30 \mu \mathrm{m}$. For the densest cross-hatch pattern (Sample 1), the weartrack depth was reduced to $\sim 20 \mu \mathrm{m}$, while the lower densities (Samples 2 and 3) resulted in a similar wear-track size of $450 \mu \mathrm{m}$ with a wear scar depth of $15 \mu \mathrm{m}$ (Figure 7).

To estimate the contribution of the mechanical and corrosion wear to the total wear, tribological tests were also made in the cathodic regime (at $-0.3 \mathrm{~V}$ against $E_{\text {ref }}$ ) to determine the mechanical part of the wear. The wear-track profiles of the cathodic wear experiments were presented in the online supplementary material for Figure 1. The trend in wear-track size was similar to that observed under OCP conditions (Figure 7).

The effect of mechanical wear on the corrosion properties was determined by measuring the wear volume. The total tribocorrosive wear, estimated as the wear volume after tribocorrosion test, is then a sum of mechanical and synergistic wear, as described in this equation:
1. $V_{\text {tot }}=V_{\text {mech }}+V_{\text {syn }}$

$V_{\text {tot }}$ was the total wear that was determined from the tribocorrosion experiments in Hank's solution. $V_{\text {mech }}$ was the mechanical wear that was estimated from the experiments executed in the cathodic regime at $-0.3 \mathrm{~V}$ against $E_{\text {ref, }}$ where the test solution was the same as in the experiments done in the tribocorrosion manner (Hank's solution). $V_{\text {syn }}$ was the synergistic contribution to the wear, calculated from the difference between $V_{\text {tot }}$ and $V_{\text {mech }}$. The total wear was higher for the laser-textured samples than for the as-received alpha-beta titanium alloy. For the as-received sample, the densest cross-hatch pattern (Sample 1; $\Delta x=100 \mu \mathrm{m}$ ) and the dimple-textured sample (Sample 4) synergistic contribution to the total wear was observed (green bar in Figure 8). For the as-received alpha-beta titanium alloy and dimpletextured surface, the synergistic contribution was $\sim 40 \%$ and dropped 
below $0.5 \%$ for the densest cross-hatch pattern (Sample 1). However, for samples with broader laser-texturing patterns (Samples 2 and 3), the mechanical wear was equal to the tribocorrosion wear, indicating no synergistic contribution. Namely, the depth of the wear track was within the thickness of the laser-induced layer with excessive amount of oxygen due to laser texturing. For this reason, the mechanical and tribocorrosion wear volumes were similar. This observation was unique and differed significantly between laser-textured titanium alloy surfaces compared to ordinary titanium alloy surfaces. The increase in the mechanical wear component, observed for the lasertextured samples, although having a harder and more wear resistant martensitic microstructure on the surface, ${ }^{24}$ is attributed to the presence of very hard and consequently brittle bulges around the textures, which form hard abrasive particles during sliding, thus intensifying the abrasive-wear component. The largest density as well as thickness of the melted and resolidified material was found for the dimple-textured sample, also showing the highest mechanical wear. The large impact of hard abrasive particles was confirmed by the highest hardness increase and the hardening effect observed within the wear track of the dimple-textured sample. The high degree of mechanical wear for the dimple-textured surface was followed by the densest cross-hatch pattern. Although the texturing densities of Sample 4 (dimples) and Sample 1 (cross-hatch, $\Delta x=100 \mu \mathrm{m}$ ) are similar, the thickness of re-solidified layer and the height of the bulges are smaller for the cross-hatch pattern, thus resulting in a smaller abrasive effect and less mechanical wear. Reducing the channel density further reduces the impact of the bulges and the component of mechanical wear. However, when the channel density

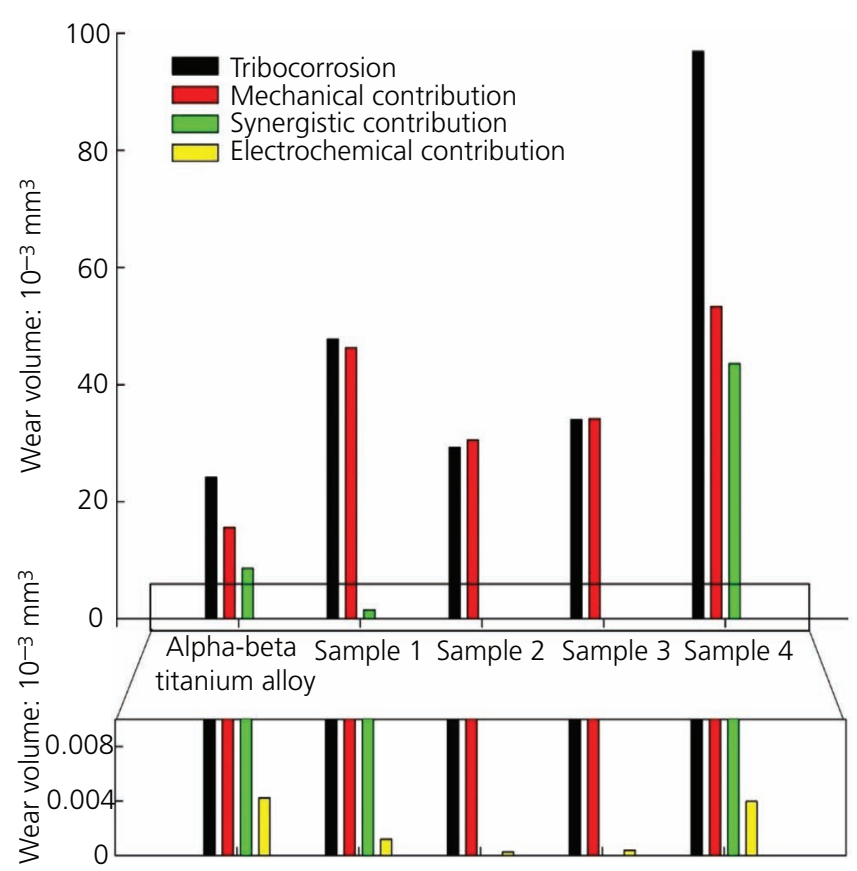

Figure 8. Contribution of mechanical wear to tribocorrosive wear in Hank's solution for a 5-N applied load. Below, zoomed-in, smaller scale view for observing the electrochemical contribution drops below a certain threshold (approximately 25\%), the impact of the bulges settles down and becomes independent of the texturing density.

As shown in a smaller scale view at the bottom of Figure 8, the electrochemical contribution, deduced from electrochemical measurements, was also the highest for the as-received and dimpletextured samples. As explained by the potentiodynamic measurements (Figure 4, Table 1), in the case of the as-received sample, this result is related to the thinner oxide layer in comparison to the laser-textured samples (discussed in Section 4, Figure 9). However, similar corrosion resistance in the case of the dimples can be explained by the combined effect of the superhydrophilicity and the increased oxide layer thickness. The electrochemical contribution is thus very low if the samples are only exposed to Hank's solution. The wear rate increases when mechanical wear is introduced in corrosive media. Since mechanical wear is a substantial contribution to the total wear, it can be concluded that the tested alpha-beta titanium alloy is relatively corrosion-stable under simulated physiological conditions due to its passive nature and mechanical wear mainly defines its tribocorrosion behaviour. Furthermore, the thicker the oxide and the re-solidified layer and the higher the bulges around the textures, the easier it will break under sliding, causing the removal of the surface layer and intensifying both the mechanical and corrosive wear components.

\section{XPS analysis}

XPS analyses were performed on the as-received and the lasertextured samples to gain insight into the surface chemistry. The XPS surface spectrum on the as-received sample showed the presence of carbon (63.7 at.\%), oxygen (27.3 at.\%), titanium (3.1 at.\%), aluminium (1.8 at.\%), vanadium (0.2 at.\%), silicon (1.5 at.\%), calcium (1.2 at.\%) and zinc ( $\mathrm{Zn})(1.2$ at.\%). On the laser-textured titanium-aluminium-vanadium alloy sample (Sample 1), the elements carbon (40.8 at.\%), oxygen (44.4 at.\%), titanium (11.6 at.\%), aluminium (2.4 at.\%) and vanadium (0.9 at.\%) were detected. The elements aluminium and titanium were present on the surface as oxides. The titanium $2 \mathrm{p}$ spectrum had a peak at $458.6 \mathrm{eV}$ associated with the titanium cation $(\mathrm{Ti}(4+))$ oxidation state and the aluminium $2 \mathrm{p}$ spectrum had a peak at $74.0 \mathrm{eV}$ associated with the aluminium cation $(\mathrm{Al}(3+))$ oxidation state. XPS depth profiles of the distribution of the elements in the subsurface region were recorded up to a depth of $35 \mathrm{~nm}$ on both samples. They are shown in Figure 9. On the asreceived sample, the oxide layer found consisted mainly of titanium dioxide $\left(\mathrm{TiO}_{2}\right)$ with a smaller amount of aluminium oxide. In total, the thickness of the oxide layer on as-received sample was estimated to be about $7 \mathrm{~nm}$ (Figure 9(a)). In the oxide layer, a significant amount of carbon ( $\sim 35$ at.\%) was also detected, probably originating from the surface contamination, as well as a small concentration of vanadium $(\sim 0.5$ at.\%). After laser texturing, the thickness of the surface layer increased (Figure 9(b)). An XPS depth profile was performed up to $35 \mathrm{~nm}$ and found that the layer with oxygen on the laser-textured sample was thicker than $35 \mathrm{~nm}$ and the oxide layer/ substrate interface was not reached. The oxide layer on the lasertextured sample mainly consisted of titanium dioxide with a small amount of aluminium oxide and a very small concentration of 


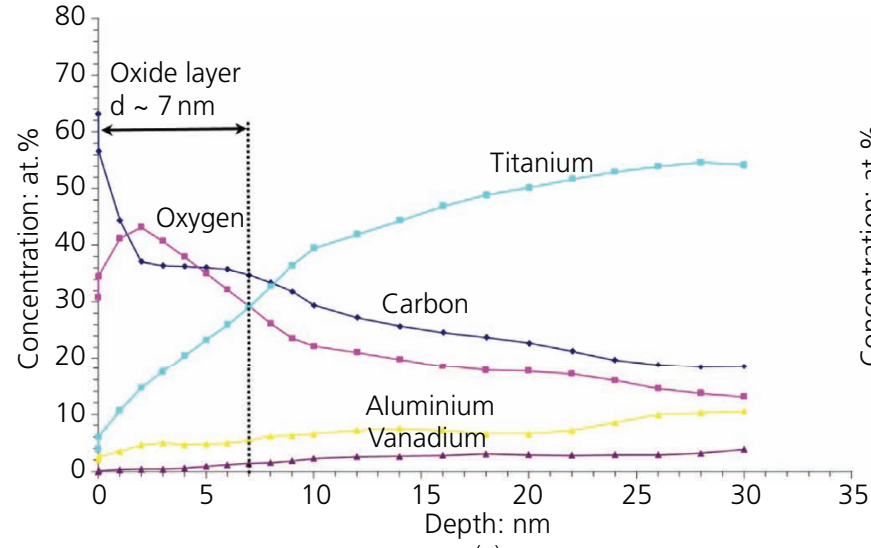

(a)

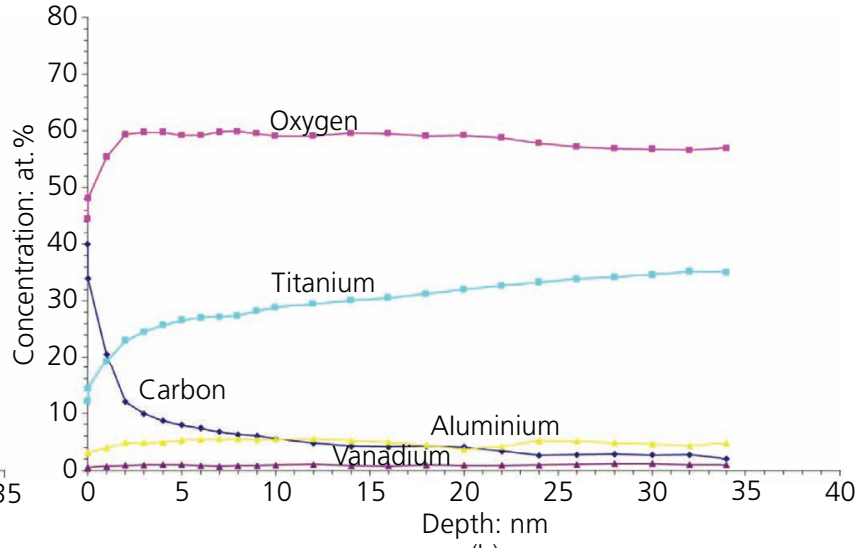

(b)

Figure 9. XPS depth profiles for (a) as-received alpha-beta titanium alloy sample and (b) laser-textured Sample 1 with $\Delta x=100 \mu \mathrm{m}$

vanadium (about 1 at.\%). The presence of alpha case layer on lasertextured Ti-alloy surfaces will be further analysed in future studies. ${ }^{23}$ The XPS results showed similar compositions of the oxide layers on both the as-received and laser-textured samples when comparing the presence of elements in the surface layers. There was, however, a significant difference in the oxide layer thickness between the two, which might influence an important contribution to the lowering of corrosion current densities of laser-textured surfaces. As shown by Mukherjee et al., ${ }^{24}$ the corrosion resistance properties of alpha-beta titanium alloy are credited to the presence of stable metal oxides of titanium, aluminium, and vanadium on the surface. However, segregation of alloying elements led to the formation of aluminiumrich $\alpha$ phases and vanadium-rich $\beta$ phases of alpha-beta titanium alloy, with the latter one being relatively less corrosion-resistant. Formation of micro-galvanic cells between the vanadium-rich and aluminium-rich phases was another obstacle. Upon laser texturing and associated martensitic phase transformation was thicker, more compact and stable top oxide film was formed, showing uniform distribution of aluminium and vanadium oxide clusters in the titanium dioxide matrix, resulting in improved corrosion resistance. ${ }^{27}$

\section{Conclusions}

An evaluation was done on the impact of surface morphology on the synergistic effect between the corrosion and the mechanical properties of the patterned alpha-beta titanium alloy in human body conditions. A nanosecond Nd-YAG laser with a $1064 \mathrm{~nm}$ wavelength was used to modify the morphology of alpha-beta titanium alloy surfaces with two different textures: cross-hatch with varying scan-line separations, $\Delta x=100,180$ and $280 \mu \mathrm{m}$, and dimples of $200 \mu \mathrm{m}$ size.

Potentiodynamic measurements showed significantly improved corrosion resistance for cross-hatch laser-textured samples due to increased hydrophobicity. The lowest corrosion rate, $1 \mu \mathrm{m} /$ year, was observed for the cross-hatch texture with $\Delta x=180 \mu \mathrm{m}$. Tribocorrosive experiments in Hank's solution indicated that laser surface texturing of alpha-beta titanium alloy in the form of crosshatch pattern reduced the friction under lubricated conditions, from 0.38 for as-received sample down to 0.34 for $\Delta x=180$ and $280 \mu \mathrm{m}$. Reduced friction was related to the increased hydrophobicity and hydrodynamic effects induced by channels. On the other hand, dimple-laser texturing resulted in the formation of thick hardened brittle layer and bulges around the dimples, which break during sliding and cause a ploughing effect and increased $C_{\mathrm{OF}}(0.37)$.

In terms of wear, the mechanical wear is shown to have a substantial contribution to the total wear and therefore, mainly defines the tribocorrosion behaviour of the laser-textured samples under investigation. Good corrosion stability of the laser-textured samples can be attributed to the passive nature of the alpha-beta titanium alloy. Furthermore, the thicker the oxide and re-solidified layers and the higher the bulges around the textures, the easier they will break under sliding, causing the removal of the surface layer and intensifying both the mechanical and corrosive wear components.

\section{Acknowledgements}

The authors acknowledge the financial support from the Slovenian Research Agency (research core funding P2-0132, P2-0273 and P2-0270. Thanks also to Dr. Mirjam Bajt Leban for helpful discussions on the surface layer properties of titanium alloys when exposed to heat.

\section{REFERENCES}

1. Runa MJ, Mathew MT and Rocha LA (2013) Tribocorrosion response of the Ti6Al4V alloys commonly used in femoral stems. Tribology International 68: 85-93, https://doi.org/10.1016/j.triboint.2013.09. 022 .

2. Sidhu SS, Singh $\mathrm{H}$ and Gepreel MAH (2021) A review on alloy design, biological response, and strengthening of $\beta$-titanium alloys as biomaterials. Materials Science Engineering $C$ 121: 111661, https://doi.org/10.1016/J.MSEC.2020.111661.

3. Devgan S and Sidhu SS (2020) Potential of electrical discharge treatment incorporating MWCNTs to enhance the 
corrosion performance of the $\beta$-titanium alloy. Applied Physics $A$ 126(3): 1-16, https://doi.org/10.1007/s00339-020-3391-1.

4. Lin N, Li D, Zou J et al. (2018) Surface texture-based surface treatments on Ti6Al4V titanium alloys for tribological and biological applications: a mini review. Materials 11(4): 487, https:// doi.org/10.3390/ma11040487.

5. Attanasio A, Gelfi M, Pola A, Ceretti E and Giardini C (2013) Influence of material microstructures in micromilling of Ti6Al4V alloy. Materials 6(9): 4268-4283, https://doi.org/10.3390/ma6094268.

6. Attar H, Ehtemam-Haghighi S, Kent D et al. (2017) Nanoindentation and wear properties of $\mathrm{Ti}$ and $\mathrm{Ti}-\mathrm{TiB}$ composite materials produced by selective laser melting. Materials Science Engineering A $\mathbf{6 8 8}$ : 20-26, https://doi.org/10.1016/j.msea.2017.01.096.

7. Silva D, Churiaque C, Bastos I and Sánchez-Amaya J (2016) Tribocorrosion study of ordinary and laser-melted Ti6Al4V alloy. Metals 6(10): 253, https://doi.org/10.3390/met6100253.

8. Kulkarni M, Mazare A, Gongadze E et al. (2015) Titanium nanostructures for biomedical applications. Nanotechnology $\mathbf{2 6}$ article 062002, https://doi.org/10.1088/0957-4484/26/6/062002.

9. Li Y, Yang C, Zhao H et al. (2014) New developments of Ti-based alloys for biomedical applications. Materials 7(3): 1709-1800, https:// doi.org/10.3390/ma7031709.

10. Bansal DG, Eryilmaz OL and Blau PJ (2011) Surface engineering to improve the durability and lubricity of Ti-6Al-4V alloy. Wear 271(9-10): 2006-2015, https://doi.org/10.1016/J.WEAR.2010.11.021.

11. Li G, Qu S, Ren Z and Li (2017) Surface modification layer of Ti-6Al$4 \mathrm{~V}$ produced by surface rolling and thermal oxidation. Surface Innovations 5(4): 232-242, https://doi.org/10.1680/jsuin.17.00005.

12. Liu X, Chu PK and Ding C (2004) Surface modification of titanium, titanium alloys, and related materials for biomedical applications. Materials Science Engineering R Reports 47(3-4): 49-121, https:// doi.org/10.1016/J.MSER.2004.11.001.

13. Li S, Zhu M, Liu J et al. (2014) Enhanced tribological behavior of anodic films containing SiC and PTFE nanoparticles on Ti6Al4V alloy. Applied Surface Science 316: 28-35, https://doi.org/10.1016/j. apsusc.2014.07.088

14. Cai JB, Wang XL, Bai WQ et al. (2013) Bias-graded deposition and tribological properties of Ti-contained a-C gradient composite film on Ti6Al4V alloy. Applied Surface Science 279: 450-457, https://doi.org/ 10.1016/j.apsusc.2013.04.136.

15. Akesso L, Navabpour P, Teer D et al. (2009) Deposition parameters to improve the fouling-release properties of thin siloxane coatings prepared by PACVD. Applied Surface Science 255(13-14): 6508-6514, https://doi.org/10.1016/j.apsusc.2009.02.032.

16. Hu T, Hu L and Ding Q (2012) The effect of laser surface texturing on the tribological behavior of Ti-6Al-4V. Proceedings of the Institution of Mechanical Engineers, Part J: Journal of Engineering Tribology 226: 854-863, https://doi.org/10.1177/1350650112450801.

17. Han Y, Liu F and Zhang K (2021) A study on tribological properties of textured Co-Cr-Mo alloy for artificial hip joints. International Journal of Refractory Metals and Hard Materials 95: article 105463, https://doi.org/10.1016/j.ijrmhm.2020.105463.

18. Conradi M, Kocijan A, Klobčar D and Godec M (2020) Influence of laser texturing on microstructure, surface and corrosion properties of Ti6Al-4V. Metals 10(11): 1504, https://doi.org/10.3390/met10111504.

19. Pérez Del Pino A, Serra P and Morenza JL (2002) Oxidation of titanium through Nd:YAG laser irradiation. Applied Surface Science 197-198: 887-890, https://doi.org/10.1016/S0169-4332(02) 00447-6.

20. Ganne A, Maslakov KI and Gavrilov Al (2017) Anti-icing properties of superhydrophobic stainless steel mesh at subzero temperatures. Surface Innovations 5(3): 154-160, https://doi.org/10.1680/jsuin.17. 00026.

21. Pfleging W, Kumari R, Besser $H$, Scharnweber T and Majumdar JD (2015) Laser surface textured titanium alloy (Ti-6Al-4V): part 1-surface characterization. Applied Surface Science 355: 104-111, https://doi. org/10.1016/j.apsusc.2015.06.175.

22. Babu DP, Vignesh S, Vignesh M and Balamurugan C (2018) Enhancement of wear resistance of Ti-6Al-4V alloy by picosecond laser surface micro texturing process. Journal of Central South University 25 1836-1848, https://doi.org/10.1007/s11771-018-3873-x.

23. Sefer B, Roa J, Mateo A, Pederson R and Antti ML (2016) Evaluation of the bulk and alpha-case layer properties in Ti-6Al-4V at micro- and nano-metric length scale. In Proceedings of the 13th World Conference on Titanium (Venkatesh V, Pilchak AL, Allison JE et al. (eds)). John Wiley \& Sons Inc., Hoboken, NJ, USA, pp. 1619-1624.

24. Mukherjee S, Dhara S and Saha P (2021) Enhanced corrosion, tribocorrosion resistance and controllable osteogenic potential of stem cells on micro-rippled Ti6Al4V surfaces produced by pulsed laser remelting. Journal of Manufacturing Processes 65: 119-133, https:// doi.org/10.1016/J.JMAPRO.2021.03.023.

25. Podgornik B (2017) In ASM Handbook: Friction, Lubrication, and Wear Technology. ASM International, Materials Park, OH, USA, pp. 706-722.

26. Schneider J, Braun D and Greiner C (2017) Laser textured surfaces for mixed lubrication: influence of aspect ratio, textured area and dimple arrangement. Lubricants 5(3): 32, https://doi.org/10.3390/ lubricants5030032.

27. Singh R, Kurella A and Dahotre NB (2006) Laser surface modification of Ti-6Al-4V: wear and corrosion characterization in simulated biofluid. Journal of Biomaterials Applications 21: 49-73, https://doi. org/10.1177/0885328206055998.

\section{How can you contribute?}

To discuss this paper, please submit up to 500 words to the journal office at journals@ice.org.uk. Your contribution will be forwarded to the author(s) for a reply and, if considered appropriate by the editor-in-chief, it will be published as a discussion in a future issue of the journal.

ICE Science journals rely entirely on contributions from the field of materials science and engineering. Information about how to submit your paper online is available at www.icevirtuallibrary.com/page/authors, where you will also find detailed author guidelines. 